\title{
GNDT II LEVEL APPROACH FOR SEISMIC VULNERABILITY ASSESSMENT OF UNREINFORCED MASONRY (URM) BUILDING STOCK
}

\author{
Manjip Shakya
}

\author{
Department of Civil Engineering, Khwopa Engineering College, Bhaktapur, Nepal
}

\begin{abstract}
Unreinforced Masonry (URM) structures, such as historic buildings, traditional buildings and ordinary buildings, exist all over the world and constitute a relevant part of the cultural heritage of humanity. Their protection against earthquakes is a topic of great concern among the earthquake engineering research community. This concern mainly arises from the strong damage or complete loss suffered by these types of structures when subjected to earthquake and also from the need and interest to preserve them as a built heritage.
\end{abstract}

This paper initially presents a methodology for assessing the seismic vulnerability of URM buildings based on vulnerability index evaluation approach. Moreover, this paper presents the correlation between vulnerability index and Macroseismic method to estimate the physical damage in relationship with seismic intensity. Finally, presents implementation of the methodology to construct vulnerability curves, fragility curves and estimate losses.

Keywords: Unreinforced buildings; Vulnerability index; Fragility curve; Macroseismic method; loss assessment

\section{Introduction}

Masonry is one of the oldest known building materials still in use for the construction of modern building systems, although modern masonry has evolved considerably from its ancient origins. However, design and construction of especially URM buildings are carried out in a traditional manner based on experience but without using any scientific methods and engineering tools. Traditional masonry structures are able to resist gravitational actions, but as they were not explicitly designed to withstand seismic loading, show particularly weakness with regard to horizontal loadings induced by a strong motion (Pineda et al., 2011). Moreover, the limited ductility of the masonry generally provides a brittle structural behaviour (Abruzzese et al., 2009). This is why a significant percentage of physical losses in past earthquakes have been due to insufficient performance of non-engineered

\footnotetext{
*Corresponding author: Manjip Shakya

Department of Civil Engineering, Khwopa Engineering

College, Libali-2, Bhaktapur, Nepal

Email: shakya.manjip@khec.edu.np

(Received: 2015 June 09 Accepted: 2015 July 01)
}

masonry buildings with low construction quality (D'Ambrisi et al., 2012; Russo et al., 2010). Considering this fact and with the continuing search for economy and new forms in the built environment, traditional masonry has been replaced by the modern time materials such as steel and concrete. But it is also a fact that in most of the earthquake prone regions of the world, especially in the developing countries, significant percentage of the building stock is composed of unreinforced and non-engineered masonry buildings that are used for residential purposes.

This paper presents a methodology for assessing the seismic vulnerability of URM buildings based on vulnerability index evaluation method. This methodology evaluates the seismic vulnerability index for the structure. Here, qualitative as well as quantitative parameters are defined to evaluate the vulnerability index. Finally, the evaluated vulnerability index, $I_{v}$, in relationship with seismic intensity can be used to estimate the physical damage, construct vulnerability and fragility curves 
and estimate losses.

\section{Proposed methodology for vulnerability assessment}

In general terms, vulnerability measures the amount of damage caused by an earthquake of given intensity over a structure (Orduña et al., 2008). However, amount of damage and seismic intensity are concepts without a clear and rigorous numerical definition. According to Sandi (1986), seismic vulnerability is an intrinsic property of the structure, a characteristic of its own behaviour due to the action of an earthquake described through a law of cause-effect, where the cause is the seismic action and the effect is the damage. However, the amount of damage identified in the seismic vulnerability assessment of buildings depends on many factors such as intensity of the seismic action, soil conditions, constructive materials, structural elements and conservation state.

There are a variety of methodologies proposed by different authors for the seismic vulnerability assessment of buildings. The selection of a certain methodology of evaluation depends on the next aspects: nature and objective of the study, available information, characteristics of the building or group of buildings under study, suitable methodology of assessment (qualitative or quantitative) and the organism which will receive the results of the study (e.g. government, scientific organizations, companies and so on).

The vulnerability index formulation proposed in this paper is the GNDT II level approach, presented in GNDT-SSN (1994), for the vulnerability assessment of URM buildings. GNDT II level approach is commonly used to identify and to characterize the potential seismic deficiencies of a building or group of buildings by means of a qualification by points for every significant component of the structure. This methodology is based on post-seismic damage observation and survey data covering a vast number of elements, focusing on the most important aspects and features that define building damage. One of the most famous methods usually found in the relevant literature corresponds to the developed by Benedetti \& Petrini et al. (1984) and the GNDT-1990 (1990). This method has been widely used in Italy during the last decades and has been upgraded as a result of the continuous experimentation and observed damage of certain types of structures (mainly URM buildings) after earthquakes of different intensities, resulting in an extensive database of damage and vulnerability.

In this approach, the overall vulnerability is calculated as the weighted sum of 14 parameters used in the formulation of the seismic vulnerability index. The 14 parameters are listed, as shown in Table 1, categorised into four groups. The first group includes parameters $(\mathrm{P} 1, \mathrm{P} 2)$ characterising the building resisting system and the type and quality of masonry, from the material (size, shape and stone type), masonry fabric and arrangement and quality of connections amongst the walls. Parameter P3 estimates the shear strength capacity of the building. Parameter P4 evaluates the potential out-of-plane collapse conditions. Parameters P5 and P6 evaluate the height and the soil foundation conditions of the buildings. The second parameter group is mainly focussed on the buildings relative location in the aggregate and on its interaction with other buildings (parameter P7). This feature is not contemplated in other methodologies and is highly important, because the building aggregate seismic response is very different from a single building response. Parameters P8 and P9 evaluate the irregularity in plan and height. Parameter P10 identifies the regularity of openings due to its importance in the load path. The third parameter group, with resource to parameters $\mathrm{P} 11$ and $\mathrm{P} 12$, evaluates horizontal structural systems, namely the type of connection of the timber floors and the impulsive nature of the pitched roofing systems. Finally, parameter P13 evaluates the structural fragilities and conservation level of the building, and parameter P14 the negative influence of nonstructural elements with poor connection conditions to the main structural system.

These 14 vulnerability assessing parameters are related to 4 classes of increasing vulnerability: A, B, $\mathrm{C}$ and D. Depending on the parameter and the selected class, the method assigns a numerical value $\left(K_{i}\right)$ ranging from 0 to 50 , which is affected by a coefficient of importance (Weight ' $W_{i}$ '). A weight $\left(W_{i}\right)$ is assigned to each parameter, ranging from 0.25 for the less important parameters (in terms of structural vulnerability) up to 1.5 for the most 
important. It reflects the importance of each parameter in the evaluation of the seismic vulnerability of the slender structure. As a final stage the seismic vulnerability index $\left(I_{v}\right)$ of the structure will be obtained with the use of equation presented in Table 1. The vulnerability index obtained as the weighted sum of the 14 parameters initially ranges between 0 and 650 , with the value then normalized to fall within the range $0 \leq I_{v} \leq$ 100 . The calculated vulnerability index can then be used to estimate structural damage after a specified intensity of a seismic event.

\section{Correlation between GNDT II approach and Macroseismic method}

The method proposed here is based on the original GNDT II level approach although with some modifications. However the major parameters, shared by every vulnerability assessment according to Combescure et al. (2005), are essentially the same. Considering this fact, the similarity in terms of the definition of the vulnerability index of the two methodologies (original and improved) enables the use of the same vulnerability functions relating vulnerability to a damage index (Benedetti \& Petrini, 1984). Since this study adopted the analytical vulnerability curves of the Macroseismic method (Giovinazzi \& Lagomarsino, 2004)), it is essential to establish the correspondence between the Macroseismic method and the GNDT II level approach.

Table 1. Vulnerability index $\left(\mathrm{I}_{\mathrm{v}}\right)$

\begin{tabular}{|c|c|c|c|c|c|c|c|}
\hline \multirow{2}{*}{$\begin{array}{l}\text { Parameter } \\
\text { group }\end{array}$} & \multirow{2}{*}{ Parameter } & \multicolumn{4}{|c|}{ Class $\left(K_{i}\right)$} & \multirow{2}{*}{$\begin{array}{c}\text { Weight } \\
\left(W_{i}\right)\end{array}$} & \multirow{2}{*}{$\begin{array}{l}\text { Vulnerability } \\
\text { index }\end{array}$} \\
\hline & & $\mathrm{A}$ & $\mathrm{B}$ & $\mathrm{C}$ & $\mathrm{D}$ & & \\
\hline \multirow{6}{*}{$\begin{array}{l}\text { 1. Structural } \\
\text { system }\end{array}$} & P1: Type of resisting system & 0 & 5 & 20 & 50 & 0.75 & \multirow{6}{*}{$I_{v}^{*}=\sum_{i=1} K_{i} W_{i}$} \\
\hline & P2: Quality of the resisting system & 0 & 5 & 20 & 50 & 1.00 & \\
\hline & P3: Conventional strength & 0 & 5 & 20 & 50 & 1.50 & \\
\hline & P4: Maximum distance between walls & 0 & 5 & 20 & 50 & 0.50 & \\
\hline & P5: Number of floors & 0 & 5 & 20 & 50 & 1.50 & \\
\hline & P6: Location and soil conditions & 0 & 5 & 20 & 50 & 0.75 & \\
\hline \multirow{4}{*}{$\begin{array}{l}\text { 2. Irregularities } \\
\text { and interaction }\end{array}$} & P7: Aggregate position and interaction & 0 & 5 & 20 & 50 & 1.50 & \multirow{4}{*}{$0 \leq I_{v}^{*} \leq 650$} \\
\hline & P8: Irregularity in plan & 0 & 5 & 20 & 50 & 0.75 & \\
\hline & P9: Irregularity in elevation & 0 & 5 & 20 & 50 & 0.75 & \\
\hline & P10: Wall façade openings and alignments & 0 & 5 & 20 & 50 & 0.50 & \\
\hline \multirow{2}{*}{$\begin{array}{l}\text { 3. Floor slabs } \\
\text { and roofs }\end{array}$} & P11: Horizontal diaphragms & 0 & 5 & 20 & 50 & 1.00 & \multirow{4}{*}{$\begin{array}{l}\text { Normalized } \\
\text { index } \\
0 \leq I_{v} \leq 100\end{array}$} \\
\hline & P12: Roofing system & 0 & 5 & 20 & 50 & 1.00 & \\
\hline \multirow{2}{*}{$\begin{array}{l}\text { 4. Conservation } \\
\text { status and other } \\
\text { elements }\end{array}$} & P13: Fragilities and conservation state & 0 & 5 & 20 & 50 & 1.00 & \\
\hline & P14: Non-structural elements & 0 & 5 & 20 & 50 & 0.50 & \\
\hline
\end{tabular}

Macroseismic Scale, which implicitly contains a model of vulnerability. On the basis of the definition of damage described in the EMS-98 scale, it is possible to derive damage probability matrices for each of the defined vulnerability classes (A to F). Through use of the linguistic definitions (Few, Many and Most) and their respective numerical interpretation, complete Damage Probability Matrices (DPM) for every vulnerability class may be obtained. Having solved the incompleteness using probability theory, the ambiguity and overlap of the linguistic definitions is then tackled using fuzzy set theory (Giovinazzi, 2005), in which upper and lower boundary limits for the correlation between the macroseismic intensity and mean damage grade $\left(\mu_{D}\right)$ of the distribution are defined and derived for each building typology and vulnerability. Mean damage grade $\left(\mu_{D}\right)$ allow us to know the expected distribution of the damage level, where it represents a quantitative interpretation of the consequences caused by the earthquake on the structural and non-structural elements (Lagomarsino et al., 2004). For the operational implementation of the methodology, an analytical expression is proposed by Bernardini et al. (2007). This expression correlates hazard with the mean damage grade $\left(0 \leq \mu_{D} \leq 5\right)$ of the damage distribution (discrete beta distribution) in terms of the vulnerability value, as shown in Eq. (1). 
$\mu_{D}=2.5+3 \tanh \left(\frac{I+6.25 \mathrm{~V}-12.7}{Q}\right) \times f(V, I)$

$0 \leq \mu_{D} \leq 5$

where, $I$ is the seismic hazard described in terms of macroseismic intensity, $V$ the vulnerability index used in the Macroseismic method and $Q$ a ductility factor that describes the ductility of a certain constructive typology (ranging from 1 to 4 ). The vulnerability index, $V$, determines the position of the curve, while the ductility factor, $Q$, determines the slope of the vulnerability function (rate of damage increases with rising intensity).

$f(V, I)=\left\{\begin{aligned} e^{\frac{V}{2} \times(I-7)}, & I \leq 7 ; \quad 0 \leq \mu_{D} \leq 5 \\ 1, & I>7\end{aligned}\right.$

where, $f(V, I)$ is a function of the vulnerability index and intensity defined in Eq. (2). The latter is introduced in order to understand the trend of numerical vulnerability curves derived from EMS98 DPMs for lower values of the intensity grades ( $I$ $=\mathrm{V}$ and VI). This analytical expression derives from the interpolation of vulnerability curves calculated from the completed DPMs, as suggested in the EMS-98 scale. It is used to estimate physical damage. This mathematical formulation is based on work previously proposed by Sandi \& Floricel (1995).

The vulnerability index, $I_{v}$, can be related to the vulnerability index, $V$ (used in the Macroseismic Method), given by Eq. (3), enabling the calculation of the mean damage grades with Eq. (1) and the subsequent estimation of physical principal, economic and human loss (Vicente et al., 2011). By comparing the vulnerability curve given by two different method of with respect to a central mean damage value $\left(\mu_{D}=2.5\right)$, the following analytical correlation was derived between the vulnerability indexes indices of the two methods:

$V=0.56+0.0064 I_{v}(3)$

\section{Implementation of the proposed methodology}

\subsection{Probability distribution of damage grade}

From mean damage grade values, $\mu_{D}$, different damage distribution histograms for events of varying seismic intensity and their respective vulnerability index values can be defined, using a probabilistic approach. The idea is to complete the EMS-98 model introducing a proper discrete probability distribution of damage grade. The most commonly applied methods are based on the binomial probability mass function and the beta probability density function and moreover, the damage distribution of masonry buildings appears to confirm quite well (Spence et al., 2003). The probability mass function (PMF) of binomial distribution is expressed in Eq. (4).

$$
\begin{aligned}
& \mathrm{PMF}=p_{k}=\frac{5 !}{k !(5-k) !} \times\left(\frac{\mu_{D}}{5}\right)^{k} \times\left(1-\frac{\mu_{D}}{5}\right)^{5-k} \\
& ; 0 \leq p \leq 1
\end{aligned}
$$

The mean damage grade, $\mu_{D}$, given by the Macroseismic method represents the mean damage value that is used to define a discrete damage distribution and is expressed as in Eq. (5). It ranges from 0 to 5 and is the barycentric value of the discrete damage distribution.

$\mu_{D}=\sum_{k=0}^{5} p_{k} \times D_{k}$

where, $p_{k}$ is the probability of having a damage grade $D_{k}$, with $k \in[0,5]$.

In this work the damage distribution adopted was fitted to a beta distribution function. Research carried out by Giovinazzi (2005) has shown that the beta distribution is the most versatile, as by controlling the shape of the distribution, it enables the fitting of both very narrow and broad damage distributions. This continuous beta Probability Density Function (PDF) is expressed as Eq. (6).

PDF: $p_{\beta}(x)=$

$\frac{\Gamma(t)}{\Gamma(r) \Gamma(t-r)}(x-a)^{r-1} x(b-x)^{t-r-1}$

$a \leq x \leq b ; a=0 ; b=5$

where, $a, b, t$ and $r$ are the parameters of the distribution and $\Gamma$ is the gamma function.

As a function of the same parameters the mean 
value $\mu_{x}$ of the continuous variable $x$, which ranges between $a$ and $b$ and its variance $\sigma_{x}^{2}$ are related to $t$ and $r$ as expressed in Eq. (7) and Eq. (8).

$t=\frac{\mu_{x}\left(a+b-\mu_{x}\right)-a b}{\sigma_{x}^{2}}-1$

$r=t\left(\frac{\mu_{x}-a}{b-a}\right)(8)$

Parameters $t$ and $r$ control the shape of the distribution. In this study, the unique value for parameter $t$ is adopted as proposed by Giovinazzi (2005) for unreinforced old brick masonry building topology, where $t=5$ has been used to represent the variance of all possible damage distributions. In order to use the beta distribution, it is necessary to reference damage grade, $D_{k}$.

Assuming, $a=0$, and $b=5$, it is possible to calculate the probability associated with damage grade, $D_{k}$ using expression Eq. (9) as follows.

$P\left(D_{0}\right)=p(0)=$

$$
\int_{0}^{0.5} \frac{\Gamma(t)}{\Gamma(r) \Gamma(t-r)}(x-a)^{r-1}(b-x)^{t-r-1} d x
$$

$P\left(D_{k}\right)=p(k)=$

$\int_{k-0.5}^{k+0.5} \frac{\Gamma(t)}{\Gamma(r) \Gamma(t-r)}(x-a)^{r-1}(b-x)^{t-r-1} d x$

$P\left(D_{5}\right)=p(5)=$

$\int_{4.5}^{5} \frac{\Gamma(t)}{\Gamma(r) \Gamma(t-r)}(x-a)^{r-1}(b-x)^{t-r-1} d x$

Another method of representing damage using damage distribution histograms involves the use of fragility curves. The fragility curve defining the probability of reaching or exceeding each damage grade, $D_{k}$, with $k \in[0,5]$ are obtained directly from the beta cumulative density function, as expressed in Eq. (10).

$P\left(D>D_{k}\right)=1-P\left(D_{k}\right)$

Just like the vulnerability curves, fragility curves define the relationship between earthquake intensity and damage in terms of the conditional cumulative probability of reaching a certain damage state. Fragility curves are influenced by the parameters of the beta distribution function and allow for the estimation of damage as a continuous probability function.

\subsection{Seismic loss assessment}

\subsubsection{Estimation of collapses and unusable structures}

The loss estimation model adopted in this research is based on damage grades that relate the probability of exceeding a certain damage level with the probability of collapse and functional loss. Among the existing approaches based on observed damage data, the one adopted in this work has been proposed by the Italian National Seismic Survey, based on the work of Bramerini et al. (1995). This approach analysis data associated with the probability of unusable buildings to minor and moderate earthquakes that produce lower levels of structural and non-structural damage and higher mean damage values are associated to the probability of collapse (Coburn et al., 1992). In Italy, data processing undertaken by Bramerini et al. (1995) has enabled the establishment of these weighted factors and respective expressions for their use in the estimation of losses. Eq. (11) and Eq. (12) were used for the analysis of collapsed and unusable slender masonry structures respectively.

$P_{\text {collapse }}=P\left(D_{5}\right)(11)$

$P_{\text {unusable buildings }}=$

$P\left(D_{3}\right) \times W_{u P t, 3}+P\left(D_{4}\right) \times W_{u P t, 4}(12)$

where $P\left(D_{k}\right)$ is the probability of the occurrence of a certain level of damage $\left(D_{1}\right.$ to $\left.D_{5}\right)$ and $W_{u P t, 3} ; W_{u P t, 4}$ are weights indicating the percentage of buildings associated with the damage level $D_{k}$, that have suffered collapse or that are considered unusable. The values of the weighting factors presented in the SSN (Bramerini et al., 1995) and HAZUS (1999) proposals are slightly different.

\subsubsection{Estimation of Human casualties and homeless}

One of the most serious consequences of an earthquake is the loss of human life and thus one of 
the major goals of all risk mitigation strategies is ensuring human safety. Once again the Italian proposal (Bramerini et al. 1995) was used here to guarantee the typological consistency of the loss assessment procedure. The rate of dead and severely injured is projected as being $30 \%$ of the residents living in collapsed and unusable buildings, with the survivors assumed to require short term shelter. Casualty (dead and severely injured) and homelessness rates are determined via Eq. (13)and Eq. (14), respectively.

$$
\begin{aligned}
& P_{\text {collapse }}=0.3 \times P\left(D_{5}\right)(13) \\
& P_{\text {homeless }}=P\left(D_{3}\right) \times W_{u P t, 3}+P\left(D_{4}\right) \times W_{u P t, 4} \\
& +P\left(D_{5}\right) \times 0.7
\end{aligned}
$$

\subsubsection{Estimation of repair costs}

The estimated damage grade can be interpreted either economically or as an economic damage index that represents the ratio between the repair costs and the replacement costs (i.e., building value) (Benedetti \& Petrini, 1984). The correlation between damage grades and the repair/rebuilding costs can be obtained by the processing and analysis of post-earthquake damage data (Dolce et al., 2006). The correlation adopted in this work has been established by Dolce et al. (2006). The statistical values obtained by these authors are derived from analysis of the data collected, using the GNDT II approach, after the 1997 Umbria-Marche and 1998 Pollino earthquakes and are based on the estimated cost of typical repair actions for more than 50,000 buildings.

The repair cost probabilities for a certain seismic event characterized by an intensity $I, P[R \mid I]$, can be obtained from the product of the conditional probability of the repair cost for each damage level, $P\left[R \mid D_{k}\right]$, with the conditional probability of the damage condition for each level of building vulnerability and seismic intensity, $P\left[D_{k} \mid I_{v}, I\right]$, given by Eq. (15).

$$
P[R \mid I]=\sum_{D_{k}=1}^{5} \sum_{I_{v}=0}^{100} P\left[R \mid D_{k}\right] \times P\left[D_{k} \mid I_{v}, I\right]
$$

\section{Conclusion}

The vulnerability assessment methodology discussed here is based on a combination of a typological methodology and a conventional methodology, damage observation and statistical approaches. This method is far more suitable for large scale analysis, essentially for two reasons: they require less information and fewer resources. However, the uncertainties associated with the empirical vulnerability curves and the quality of vulnerability classification data are still issues that must be studied further with respect to post-seismic data collection. This methodology identifies 14 key parameters regarding the behaviour and seismic response of buildings, allowing indirect identification of structural weaknesses and common fragilities of the building stock. Integration of this vulnerability assessment technique into a Macroseismic method has enabled its application for the development of damage and loss scenarios for risk mitigation and management. In correspond with this methodology, the application of GIS tools and database management system in future may enable the storage of building feature and survey information, assessment of seismic vulnerability and damage and risk scenario prediction, as well as allow the upgrading and improvement of data. This integrated tool can be helpful for the development of strengthening strategies, cost-benefit analyses, civil protection and emergency planning.

\section{References}

[1] Abruzzese, D., Miccoli, L., Vari, A., Ferraioli, M., Mandara, A., \& Froncillo, S. (2009). Dynamic investigation of medieval masonry towers: Seismic resistance and strengthening techniques. In: Proceedings of the international conference on protection of historical buildings (PROHITEC), Rome, Italy.

[2] Benedetti, D., \& Petrini, V. (1984). Sulla vulnerabilitá sismica di edifici in muratura i proposte di un metodo di valutazione. Lindustria delle Construzioni, 149, 66-74. (In Italian).

[3] Bernardini, A., Giovinazzi, S., Lagomarsino, S., \& Parodi, S. (2007). Vulnerabilità e previsione di danno a scala territoriale secondo una metodologia macrosismica coerente con la scala EMS-98. ANIDIS, XII Convegno Nazionale l'ingegneria sismica in Italia, 10 a 14 Giugno, Pisa. 
[4] Bramerini, F., Di Pasquale, G., Orsini, A., Pugliese, A., Romeo, R., \& Sabetta, F. (1995). Rischio sismico del territorio italiano. Proposta per una metodologia e risultati preliminari. Servizio Sismico Nazionale, Rapporto Tecnico, SSN/RT/95/01, Roma.

[5] Coburn, A. W., Spence, R., \& Pomodis, A. (1992). Factors determining human casualty levels in earthquakes: mortality prediction in building collapse. In: Proceedings 10th World Conference of Earthquake Engineering, Madrid, Spain, pp. 5989-5994.

[6] Combescure, D., Guéguen, P., \& Lebrun, B. (2005). Vulnérabilité sismique du bâti existant: approche d'ensemble. Cahier technique AFPS, 25, 121. (In French)

[7] D’Ambrisi, A., Mariani, V., \& Mezzi, M. (2012). Seismic assessment of a historical masonry tower with nonlinear static and dynamic analysis tuned on ambient vibration tests. Journal of Engineering Structure, 36, 210-219.

[8] Dolce, M., Kappos, A., Zuccaro, G., \& Coburn, A. W. (1994). Report of the EAEE working group 3: vulnerability and risk analysis, Technical Report. In: Proceedings 10th European Conference on Earthquake Engineerin, Vienna, Italy, Vol. 4, pp. 3049-3077.

[9] Giovinazzi, S., \& Lagomarsino, S. (2004). A macroseismic model for the vulnerability assessment of buildings. In: Proceedings of $13^{\text {th }}$ world conference on earthquake engineering. 1- 6 August, Vancouver, Canada, Paper no. 896.

[10] Giovinazzi, S. (2005). The vulnerability assessment and damage scenario in seismic risk analysis. $\mathrm{PhD}$ Thesis, International doctorate, University of Florence, Technical University of Carolo Wilhelmina.

[11] GNDT-1990 (1990). Gruppo Nazionale per la Difesa dai Terremoti, Seismic risk of public buildings. National Council of Investigation, National Group for the earthquake protection, Italy. (in Italian)

[12] GNDT-SSN (1994). Scheda di esposizione e vulnerabilità e di rilevamento danni di primo livello e secondo livello (muratura e cemento armato). Gruppo Nazionale per la Difesa dai Terremoti: Roma, Italy. (In Italian)

[13] HAZUS MH (1999). Earthquake loss estimation methodology-technical and user manuals. Federal
Emergency Management Agency, Washington, D.C.

[14] Lagomarsino, S., Podestà, S., \& Resemini, S. (2004). Observation and mechanical models for the vulnerability assessment of monument buildings. In: Proceedings of $13^{\text {th }}$ world conference on earthquake engineering, 1- 6 August, Vancouver, Canada, Paper no. 942 .

[15] Orduña, A., Preciado, A., Galván, J. F., \& Araiza, J. C. (2008). Vulnerability assessment of churches at Colima by $3 \mathrm{D}$ limit analysis models. In: Proceedings of the $6^{\text {th }}$ International Conference on Structural Analysis of Historical Constructions, July 2-4, Bath, UK.

[16] Pineda, P., Robador, M. D., \& Gil-Martíl, M. A. (2011). Seismic Damage Propagation Prediction in Ancient Masonry Structures: an Application in the Non-Linear Range Via Numerical Models. The Open Construction and Building Technology Journal, 5, (Suppl 1-M4), 7179.

[17] Russo, G., Bergamo, O., Damiani, L., \& Lugato, D. (2010). Experimental analysis of the "Saint Andrea" Masonry Bell Tower in Venice. A new method for the determination of Tower Global Young's Modulus E". Journal of Engineering Structure, 32, 353-360.

[18] Sandi, H. (1986). Vulnerability and risk analysis for individual structures and system, Report of the European Association of Structural Engineering. In: Proceedings $8^{\text {th }}$ Congress of the European Conference on Earthquake Engineering, Lisbon, Portugal.

[19] Sandi H, \& Floricel I. (1995). Analysis of seismic risk affecting the existing IX building stock. In: Proceedings of the 10th European conference on earthquake engineering, vol 3, pp 1105-1110

[20] Spence, R., Bommer, J., Del, Re D., Bird, J., Aydinoglu, N., \& Tabuchi, S. (2003). Comparison Loss Estimation with Observed Damage: A study of the 1999 Kocaceli Earthquake in Turkey. Journal of Bulletin Earthquake Engineering, 1, 83-113.

[21] Vicente, R., Parodi, S., Lagomarsino, S., Varum, H., \& Mendes da Silva, J. A. R. (2011). Seismic vulnerability and risk assessment: case study of the historic city centre of Coimbra, Portugal. Bulletin Earthquake Engineering, 9, 1067-1096, doi:10.1007/s10518-0109233-3. 